\title{
GUARDA COMPARTILHADA COMO DISPOSITIVO DE COMBATE À ALIENAÇÃO PARENTAL: EFETIVIDADE E DIFICULDADES DA SUA APLICAÇÃ̃ ${ }^{1}$
}

GUARD SHARED AS A DEVICE FOR COMBATING PARENTAL DISPOSAL: EFFECTIVENESS AND DIFFICULTIES OF ITS APPLICATION

Henrique Alves Pereira FURLAN ${ }^{2}$

Ana Cristina GOMES ${ }^{3}$

ISSUE DOI: $10.21207 / 2675-0104.2018 .765$

\section{RESUMO}

Este trabalho busca analisar - observando a legislação, a doutrina e a jurisprudência -, a influência da Guarda Compartilhada nas hipóteses em que se decide adotar tal instituto a fim de combater a Alienação Parental ou qualquer outro tipo de trauma ou transtorno psicológico que o infante possa desenvolver. A Lei 13.058/2014 regulamenta o uso da Guarda Compartilhada como regra geral no ordenamento jurídico, visando além dos benefícios supracitados ao menor, também tenta fazer com que os pais tenham uma divisão mais harmoniosa e justa da Guarda de seus filhos, dividindo tanto as obrigações quanto o tempo junto, sem que nenhum deles seja o Guardião de fato e o outro apenas faça visitas e contribua com quantia determinada em juízo. Assim, no desenvolver da pesquisa ocorreu à análise tanto da história da Guarda Compartilhada como os diversos pontos de vista sobre ela, as dificuldades

\footnotetext{
${ }^{1} \mathrm{O}$ presente artigo sintetiza a monografia de conclusão da pesquisa, realizada para o Programa Interno de Bolsas de Iniciação Científica (PIBIC 2017-2018) da Faculdade de Direito de Franca (FDF), Franca/SP.

${ }^{2}$ Discente da Faculdade de Direito de Franca (FDF), Franca/SP. Bolsista do Programa Interno de Bolsas de Iniciação Científica (PIBIC 2017-2018).

${ }^{3}$ Graduada em Direito pela Universidade Estadual Paulista "Julio de Mesquita Filho", Mestre em Direito pela Universidade Estadual Paulista "Julio de Mesquita Filho", doutoranda pela Universidad de Salamanca na Escuela de Doctorado - Estado de Derecho y Gobernanza Global, professora colaboradora da Faculdade de Direito de Franca.
} 
enfrentadas por ela em um ordenamento jurídico engessado, ainda mais em se tratando de um assunto tão complicado dentro da seara do Direito de Família. Com o desenrolar do estudo nota-se que a posição majoritária no Brasil entende que a Guarda Compartilhada deve ser cada vez mais aplicada e que com o passar do tempo consiga se adaptar a fim de alcançar os objetivos de tal instituto jurídico. Muito importante ressaltar que se deve sempre refletir sobre formas que possam valorizar, introduzir, desconstruir preconceitos e afastar ideias equivocadas sobre esta espécie de Guarda.

Palavras-chave: Direito de Família. Guarda Compartilhada. Alienação Parental. Poder Familiar.

\section{ABSTRACT}

This paper seeks to analyze, in accordance with legislation, doctrine and jurisprudence, the influence of the Shared Guard, in the hypotheses in which it is decided to adopt such institute in order to combat Parental Alienation or any other type of trauma or psychological disorder that the infant can develop. Law 13.058 / 2014 regulates the use of Shared Guard as a general rule in the legal system, aiming at the above-mentioned benefits to the child, also tries to make parents have a more harmonious and fair division of the Guardianship of their children, dividing both the obligations as the time together, without any of them being the Guardian de facto and the other only making visits and contributing with amount determined in court. Thus, in the development of the research, the analysis of the history of the Shared Guard as well as the different points of view about it, the difficulties faced by it in a legal system embedded, even more in dealing with such a complicated subject within the field of Law family's. With the development of the study, it is noted that the majority position in Brazil understands that the Shared Guard should be increasingly applied and that, over time, be able to adapt in a way that achieves the objectives of such a legal institute. It is also very important to remember that one should always think about ways that can value, introduce, deconstruct prejudices and avoid mistaken ideas about this kind of Guard.

Keywords: Family right. Shared Guard. Parental Alienation. Family Power.

\section{INTRODUÇÃO}

É inegável que com o passar do tempo enormes mudanças ocorreram com o conceito de família, as quais fizeram com que as Leis e o Direito se desenvolvessem também para que pudessem se enquadrar de maneira adequada à situação predominante em cada época.

Sendo assim, é possível observar o Direito tratando de forma totalmente diferente as situações jurídicas provindas do desfazimento dos casamentos. Há algumas décadas, por exemplo, isso nem mesmo era possível, já que os matrimônios tinham cunho eterno e as partes envolvidas neles não podiam se separar até o fim de suas vidas. Isso foi mudando e atualmente são minoria os casamentos que não terminam antes da morte de um dos cônjuges.

Diante disso, o presente trabalho tem por intuito pesquisar doutrinariamente e jurisprudencialmente o instituto da Guarda Compartilhada, que foi adotada pela Lei 13.058/2014, como regra geral na disputa da guarda dos filhos e suas consequências, dificuldades para sua aplicação, o que realmente acontece na prática e a forma que deve ser 
aplicada para que beneficie a criança envolvida neste já complicado processo de separação dos pais. O método utilizado para desenvolver o trabalho e assim alcançar o resultado é o dedutivo, pois o trabalho parte de uma visão ampla com premissas maiores para ao fim encontrar resultados mais específicos. O método analítico também foi utilizado para possibilitar a analise jurisprudencial e doutrinaria.

A referida pesquisa tem o objetivo geral de recolher informações sobre o funcionamento da Guarda Compartilhada. Por sua vez, os objetivos específicos visam estabelecer a relação entre o instituto supracitado e a Alienação Parental, buscando também abordar o desenvolvimento de tal relação com o passar do tempo e como ela pode continuar progredindo para que um dia se consiga acabar com este problema de relevância tão grande na sociedade atual, com tamanho impacto nas famílias.

Para isso, o tema será dividido em quatro capítulos. Inicialmente, a pesquisa aborda a Guarda Compartilhada, analisando seu conceito mais amplo, para então aprofundar os estudos adentrando as consequências do uso desse instituto e as dificuldades encontradas em sua aplicação. Além de fazer um paralelo entre a legislação brasileira e a de outros países, a fim de demonstrar algumas semelhanças e peculiaridades de cada um.

Posteriormente, no segundo capítulo o foco será voltado para as consequências dos resquícios da Guarda Unilateral, vistas atualmente por conta de todo o tempo pelo qual a Guarda Unilateral foi tratada não só como regra geral, mas como única opção existente até o ano de 2008, quando a Guarda Compartilhada foi instituída, quando os legisladores perceberem a importância da divisão de responsabilidades e despesas referentes à todas as atividades da criança.

Em seguida, no terceiro capítulo, o enfoque da pesquisa é a Alienação Parental, não somente no âmbito jurídico, mas também os fatores psicológicos que influem sobre as crianças vítimas de tal fenômeno, no que consiste este conceito e o que são considerados Atos de Alienação Parental.

Ainda nesse aspecto, a pesquisa será finalizada com o quarto capítulo, que busca explicitar as medidas que podem ser tomadas contra o genitor que praticar os chamados atos de alienação e também mostrar o grande problema que vem se apresentando em relação às falsas acusações de abuso que um dos genitores faz em face do outro para ver ser deferida a Guarda Unilateral em seu favor.

As fontes que irão dar o embasamento teórico essencial para fundamentar o referido trabalho e analisar os julgados serão a lei, a 
doutrina, a jurisprudência e alguns artigos jurídicos selecionados, com o propósito de que a pesquisa obtenha seus objetivos de maneira clara, bem fundamentada e atual.

\section{NOÇÕES GERAIS}

O Código Civil de 1916 disciplinava a proteção dos filhos em seus artigos 325 a 328, nos quais era deferido o direito à guarda dos filhos menores apenas ao cônjuge não culpado pela dissolução conjugal, se a dissolução conjugal fosse por desquite amigável, o que fosse acordado entre os cônjuges quanto à guarda dos filhos menores seria colocado em prática. No entanto, se a dissolução fosse por desquite judicial, o cônjuge inocente seria o guardião dos filhos menores. Porém, se ambos os cônjuges fossem culpados pela dissolução conjugal, os filhos menores ficariam com a mãe, desde que o magistrado entendesse que esta solução não traria prejuízo de cunho moral aos menores, sendo assim havia a discricionariedade deste para decidir, desde que fossem verificados motivos graves.

Com a publicação da Lei no 6.515 de 1977 (Lei do Divórcio), foram revogados os artigos 325 a 328 do Código Civil de 1916 e a proteção da pessoa dos filhos ficou disciplinada nos artigos 9 ao 16 da mesma Lei, porém sem que fosse acrescentada modificação significativa no instituto da guarda, pois a culpa continuava sendo o principal motivador para determinar para qual dos ex-cônjuges seria concedida a guarda. Trazia ainda em seu artigo 15, como regra geral, a guarda materna: "O filho natural enquanto menor ficará sob o poder do genitor que o reconheceu e, se ambos o reconhecerem, sob o poder da mãe, salvo se de tal solução advier prejuízo ao menor".

A Lei 13.058/2014 fez com que a guarda compartilhada se tornasse regra geral nos casos de separação conjugal, buscando em primeiro plano a participação ativa dos pais na criação dos filhos, já que independentemente da separação e do término da relação conjugal, a fase de descoberta do mundo e de conhecer outras pessoas pela qual as crianças e adolescentes passam nesse período deve ser compartilhado e devidamente equilibrado entre os genitores. Antes da regulamentação legal, era adotada quase sempre a Guarda Unilateral descrita no Art. 1583 $\S 1^{\circ}$ do Código Civil que é aquela atribuída a um só dos genitores ou a quem o substitua, o detentor da guarda ficava com a responsabilidade 
exclusiva de decidir sobre a vida da criança, restando ao outro apenas supervisionar tais atribuições e visitar o menor nos dias determinados pelo juiz. Sendo que, na maioria dos casos em que se aplicava esse tipo de guarda, a detentora era a mãe. Apesar da atual conjuntura, onde a Guarda Compartilhada é a regra geral, em "Ultima Ratio", a guarda unilateral poderá ser deferida pelo juiz, assim como requerida pelas partes.

Além dos dispositivos supracitados, a relação entre pais e filhos também é pautada pela Constituição Federal nos artigos 226 a 230, que tratam justamente da importância da família na sociedade, atualmente aceitando a família independentemente da sua formação, deixando de lado a visão deteriorada de que a família só pode ser constituída por um pai, uma mãe e seus filhos.

Segundo Rodrigo da Cunha Pereira,

Guarda de filho é uma expressão que tende a acabar. É que ela traz consigo um significante que está mais para objeto do que para sujeito. Mais para posse e propriedade do que cuidado com os filhos. Assim como a expressão "visitas" foi substituída por "convivência" pelo ECA 4 .

Em análise similar, a denominação "poder familiar" é mais apropriada que "pátrio poder" utilizada pelo Código de 1916, mas não é a mais adequada, porque ainda se reporta ao "poder". Algumas legislações estrangeiras, como a francesa e a norte-americana, optaram por "autoridade parental", tendo em vista que o conceito de autoridade traduz melhor o exercício de função legítima fundada no interesse de outro indivíduo, e não em coação física ou psíquica, inerente ao conceito de poder. ${ }^{5}$

\section{DIFICULDADES NA APLICAÇÃO}

Neste tópico faz-se clara a dificuldade de aplicação da norma jurídica por haver muita diversidade no que hoje se considera família. Tais diferenças complicam a vida do legislador, que deve, ao momento da elaboração das leis, pensar em todas as situações em que a lei será aplicada e de que forma pode deixar lacuna para uma interpretação destoante da pretendida.

${ }^{4}$ PEREIRA, Rodrigo da Cunha, Guarda compartilhada: o filho não é de um nem de outro, é de ambos. Disponível em: < http://www.ibdfam.org.br >. Acesso em: 28 jul. 2018.

${ }^{5}$ TARTUCE, Flávio. Direito Civil: Direito de família. Vol.5. 2014, p. 952. 


\begin{abstract}
A realidade sempre antecede o direito. Atos e fatos tornam-se jurídicos a partir do agir das pessoas de modo reiterado. Ainda que a lei tente prever todas as situações dignas de tutela, as relações sociais são muito mais ricas e amplas do que é possível conter uma legislação. A realidade é dinâmica e a moldura dos valores juridicamente relevantes torna-se demasiado estreita para a riqueza dos fatos concretos. A existência de lacunas no direito é decorrência lógica do sistema e surge no momento da aplicação do direito a um caso sub judice não previsto pela ordem jurídica. ${ }^{6}$
\end{abstract}

Como se não fosse o suficiente, ainda há problemas quanto à aplicação da norma nos casos concretos, pois mesmo com o poder vinculante de uma Lei, muitas decisões judiciais deixam de observar este direito à Guarda Compartilhada, que se refere a pessoa da criança ou adolescente, e privilegiando alguma das partes litigantes com a Guarda Unilateral, por ainda haver certos costumes arraigados na cultura jurídica brasileira, que são muito difíceis de mudar em tão poucos anos.

Mas o principal obstáculo para o perecimento de tal dispositivo no cenário brasileiro ainda são os próprios pais, que tomados pelos sentimentos sobressalentes da relação extinta, não conseguem enxergar que o melhor para o infante é que ele conviva com os dois e tenha todo o afeto e atenção de cada um deles. Muitos criam barreiras que impedem a aplicação da Guarda Compartilhada ou então colocam barreiras para que se cumpra o que foi decidido judicialmente, praticando assim, por exemplo, a alienação parental ao falar coisas ruins e negativas do ex-cônjuge para os infantes, implantando falsas memórias.

\title{
2.1 RESQUÍCIOS DA CULTURA DA GUARDA UNILATERAL MATERNA
}

No Brasil, a Guarda Unilateral sempre foi o regime de guarda que prevaleceu em nosso ordenamento jurídico quando ocorria a separação de pais que possuíam filhos. Historicamente, na grande maioria dos casos enquanto o pai era incumbido apenas de prover o sustento da casa o Poder Familiar ficava concentrado nas mãos da mãe que cuidava da casa, da educação dos filhos e, quando havia a separação, restava ao pai pagar-lhes pensão alimentícia e quiçá visitar seu descendente de tempos em tempos. É verdade que essa distinção tem sido cada vez mais deixada de lado para buscar o equilíbrio entre os genitores. Isso pode ser percebido facilmente

${ }^{6}$ DIAS, Maria Berenice, Manual de Direito das Famílias. ed. 11. 2015, p. 45. 
em muitos lares brasileiros nos quais as mães colaboram no pagamento das despesas domésticas, ou até mesmo sustentam a família enquanto o pai cuida da família e da casa, invertendo totalmente o que costumava acontecer.

Analisando a realidade das famílias brasileiras pode-se notar que muitos homens acabaram sendo desencorajados de cuidar dos filhos por suas esposas, pois acreditavam que eles não possuem as habilidades necessárias para tal, tendo apenas uma participação que acaba por ser meramente colaborativa. Porém, essa não é uma realidade vista apenas no Brasil, pesquisas realizadas na França e na Grécia apontam que a função dos pais/homens é simplesmente a de provedor, tendo uma função de auxílio quanto aos cuidados infantis, sendo um ator coadjuvante no contexto da educação de seu filho.

Com isso, pode-se pensar que, ao mesmo tempo em que as mulheres conquistaram direitos civis e políticos que as equipararam aos homens, permanecem sendo identificada à maternidade, condição que lhes confere prerrogativas em relação ao homem-pai. Mantendo-se, assim, a antiga desigualdade entre os papéis parentais, que hoje tende a favor da figura materna. ${ }^{7}$

\title{
Segundo Aline Ferreira Dias Leite:
}

\begin{abstract}
Do trabalho e contato com a diversidade de ações processuais de separação ou divórcios judiciais, percebemos que a maioria das que demandam a atuação do assistente social envolve separação litigiosa, disputa pela guarda dos filhos, fixação de pensão alimentícia e regulamentação de visitas. Ao realizarmos os procedimentos técnicos para o estudo social com a elaboração de um parecer profissional, nos deparamos com situações, no Poder Judiciário, que permitem inconformidades e diversidade de questionamentos em torno da disputa pela guarda dos filhos. Por exemplo, enquanto um casal vive uma união amorosa pautada no afeto recíproco, tanto o homem quanto a mulher são capazes de cuidar dos filhos, revelandose na maioria das vezes ótimos pais. Contudo, quando ocorre o término da relação conjugal, um deles se transforma em um ser "perigoso", aos olhos do outro e do próprio Poder Judiciário, não podendo mais cuidar do filho, não mantendo a convivência preservada e não exercendo o seu papel familiar. Nesse caso, um deles fica alijado da convivência com os filhos e tem que aguardar despacho judicial para obter o direito de vê-los em dias e horários regulamentados pela justiça. Sobre esse prisma, percebemos a naturalidade com que um dos pais é transformado em um ser completamente adverso do que era anteriormente. Torna-se um
\end{abstract}

${ }^{7}$ SOUSA, Analicia Martins de. Síndrome da Alienação Parental: Análise de Um Tema em Evidência. Dissertação (Pós-Graduação em Psicologia Social): Universidade do Estado do Rio de Janeiro (UERJ/RJ). 2009, p. 68. 
indesejável, "perigoso", e pessoa que pode colocar a vida do menor em risco, uma vez que começará a trilhar sua vida em busca de novas satisfações e realizações pessoais. ${ }^{8}$

Maior consequência disso é que a maioria esmagadora das mães que se divorciam, acha que os filhos devem ficar sob sua guarda, não aceitando, por exemplo, a Guarda Compartilhada, e acabam por criar barreiras de forma que o judiciário não possa aplicá-la, chegando até a fazer coisas absurdas como fazer falsas acusações de que o pai cometeu algum tipo de abuso sexual ou agrediu o filho em questão. Deixando de lado os direitos e o bem do menor e nessas ultimas ocasiões até mesmo a honra do genitor e sua própria moral, agindo claramente de má-fé para prejudicar o outro de forma que consiga ter o infante sob seu único e exclusivo domínio.

\section{CONSEQUÊNCIAS DA LEI № $13.058 / 14$}

Em verdade, as modificações introduzidas pela Lei $n^{\circ} 13.058 / 14$ quanto ao instituto da guarda compartilhada vêm para atender uma espécie de incompreensão pelo poder judiciário da Lei anterior. Incompreensão essa que mantinha as crianças no déficit emocional, causa de tantos transtornos psicológicos já conhecidos pelos estudos de alto nível e dos riscos de maus tratos ou abusos por terceiros e pela observação de que a guarda unilateral não vinha obtendo efetividade no convívio familiar.

Esse tipo de guarda tem como um de seus objetivos, excluir a sensação de abandono causado pela separação dos genitores e a Alienação Parental por parte do genitor que possui a Guarda Unilateral, possibilitando assim o contato diário e mantendo-se o vínculo sentimental com os mesmos. Sendo assim, favorece o convívio com estes, retirando da criança o fardo de ter que escolher entre o pai ou a mãe, além disso, a criança pode desta forma manter contato com parentes de ambas as famílias, tendo como princípio tem o disposto por Silvio de Salvo Venosa: "A ideia é fazer com que pais separados compartilhem da educação, convivência e evolução dos filhos em conjunto. Em essência, essa atribuição reflete o compromisso dos

\footnotetext{
${ }^{8}$ LEITE, Aline Ferreira Dias. Primazia da guarda materna: A guarda compartilhada como alternativa de mudança. Dissertação (Doutorado em Assistência Social): Pontifícia Universidade Católica de São Paulo (PUC/SP). 2015, p.62.
} 
pais de manter dois lares para seus filhos e cooperar de forma conjunta em todas as decisões"9.

\section{ALIENAÇÃO PARENTAL}

\section{$5.1 \quad$ NOÇÕES GERAIS}

A Alienação Parental é um fenômeno que começou a ser estudado somente nas últimas décadas, quando passou a ser observado com um olhar mais crítico a partir do reconhecimento dos profissionais da área médica que vem tentando alertar sobre a gravidade do problema, obtendo também o apoio do Poder Executivo, que criou a Lei n..$^{\circ}$ 12.318/2010 para regular a Alienação Parental e definir os chamados Atos de Alienação Parental, além do Poder Judiciário, que aplica este dispositivo legal para reprimir esses atos.

Os Atos de Alienação Parental, foram regulados por meio de um rol meramente exemplificativo encontrado em seu $\S 2^{\circ}$ pela Lei n. $^{\circ}$ 12.318/2010, proveniente do Projeto de Lei ${ }^{\circ} 4.053 / 2008$, aprovado por unanimidade pela Comissão de Seguridade Social e Família da Câmara dos Deputados, e pela Comissão de Constituição e Justiça do Senado, a fim de acabar com a prática de abusos psicológicos com crianças. Além desta previsão legal, a proibição quanto à Alienação Parental também encontra fundamentação constitucional no princípio da paternidade responsável, prevista no art. $226, \S 7^{\circ} \mathrm{da} \mathrm{CF} / 88$.

Em seu artigo art. $2^{\circ}$, a Lei $n^{\circ} 12.318 / 2010$ traz:

Considera-se ato de alienação parental a interferência na formação psicológica da criança ou do adolescente promovida ou induzida por um dos genitores, pelos avós ou pelos que tenham a criança ou adolescente sob a sua autoridade, guarda ou vigilância para que repudie genitor ou que cause prejuízo ao estabelecimento ou à manutenção de vínculos com este.

Parágrafo único. São formas exemplificativas de alienação parental, além dos atos assim declarados pelo juiz ou constatados por perícia, praticados diretamente ou com auxílio de terceiros:

I - Realizar campanha de desqualificação da conduta do genitor no exercício da paternidade ou maternidade;

${ }^{9}$ VENOSA, Silvio de Salvo, Direito Civil. Direito de Família, Vol. 6, 12 ${ }^{\text {a }}$ Ed. Editora Atlas, São Paulo, 2014, p. 91. 


\begin{abstract}
II - Dificultar o exercício da autoridade parental;
III - Dificultar contato de criança ou adolescente com genitor;

IV - Dificultar o exercício do direito regulamentado de convivência familiar;

V - Omitir deliberadamente a genitor informações pessoais relevantes sobre a criança ou adolescente, inclusive escolares, médicas e alterações de endereço;

VI - Apresentar falsa denúncia contra genitor, contra familiares deste ou contra avós, para obstar ou dificultar a convivência deles com a criança ou adolescente;

VII - Mudar o domicílio para local distante, sem justificativa, visando a dificultar a convivência da criança ou adolescente com o outro genitor, com familiares deste ou com avós.
\end{abstract}

No parágrafo único do artigo transcrito acima, é exposto que esse não é um rol taxativo das maneiras de se praticar a Alienação Parental, ficando à cargo do juiz decidir o que se enquadra nesses atos e deverá sofrer sanções de acordo com a gravidade deles.

\title{
5.2 SÍNDROME DA ALIENAÇÃOPARENTAL
}

Ao tratar de processos de divisão de Guarda de menores, é imprescindível que sejam levados em consideração os efeitos psicológicos de cada medida que venha a ser adotada, sendo a saúde física e mental da criança o foco de qualquer discussão.

Tendo isso em vista, em 2010 foi instituída a Lei $\mathrm{n}^{\circ}$ 12.318, conhecida como Lei da Alienação Parental, em seu artigo $2^{\circ}$ traz, um rol taxativo do que pode ser considerado como Ato de Alienação Parental e a sua definição perante o Direito brasileiro:

A Síndrome de Alienação Parental (SAP), conhecida por muitos pela expressão "implantação de falsas memórias" ${ }^{10}$, é um conceito que foi criado pelo estadunidense Richard Gardner, psiquiatra infantil, em 1985, e considera tal trauma psicológico como uma das consequências provocadas em crianças que são ou foram expostas a atos de alienação, quase sempre seus efeitos são demonstrados durante ou após a separação dos pais.

Segundo Gardner, esta é uma síndrome que se configura quando a criança passa a demonstrar um sentimento de profundo repúdio por um dos progenitores desenvolvido ao longo do tempo, mas sem qualquer tipo de justificativa plausível.

\footnotetext{
${ }^{10}$ JUNIOR, Eloy Pereira Lemos. Alienação Parental: Uma Análise Da Lei 12.318/2010, p.09.
} 
Este fenômeno está presente na sociedade desde muito tempo atrás, porém, nunca houve por parte do Estado alguma forma de proteção legal específica, mesmo que o Código Civil já especificasse por meio de seu art. 1.638 as situações em que o pai ou a mãe poderão perder o poder familiar por ato judicial.

\subsection{A PRÁTICA DA ALIENAÇÃO PARENTAL}

Como já explanado no capítulo passado, a prática da Alienação Parental é um dos maiores motivos para que um genitor perda a Guarda de seu filho, devendo ressaltar que isso não ocorre em todos os casos, tais medidas devem ser adotadas sempre levando em consideração a proporcionalidade entre o ato de Alienação, os danos causados ao infante e a sanção que será deferida contra ele.

Tomando como exemplo de alienação a mudança abusiva de endereço, recorre-se aos ensinamentos de Gonçalves, ao se referir a Lei ${ }^{\circ}$ 12.318/10, citando a jurisprudência do Tribunal de Justiça de Santa Catarina:

"A lei ora comentada tem mais um caráter educativo, no sentido de conscientizar os pais, uma vez que o Judiciário já vinha tomando providências para proteger o menor, quando detectado um caso da aludida síndrome. A $2^{\mathrm{a}}$ Câmara de Direito Civil do Tribunal de Justiça de Santa Catarina ${ }^{11}$, por exemplo, conforme publicação de 9 de agosto de 2010, manteve a suspensão de visitas ao pai que praticou alienação parental. Decidiu-se que o pai da criança necessitava de tratamento psicológico antes de voltar a ter permissão para as visitas. Consta do processo que a mãe, ao buscar o filho na creche, teve a criança tirada de seus braços pelo pai, de forma violenta, e, depois disso, ficou durante cinco anos sem ter informações sobre o paradeiro do menor. Durante esse período, o pai passou à criança conceitos distorcidos sobre a figura materna, para obter a exclusividade do seu afeto, com a rejeição da mãe e a manutenção do seu paradeiro em segredo. Após localizar a criança com o auxílio de programas de TV, a mãe obteve a sua guarda provisória e teve conhecimento de que, para não ser encontrado, o pai mudava-se constantemente, tendo passado

\footnotetext{
${ }^{11}$ TJSC, 2a Câm. Dir. Civil, rel. Des. Nelson Schaeffer Martins. Disponível em: <http://www.editoramagister.com. Acesso em 9-8-2010>.
} 
pela Argentina, Paraguai e Chile, além de cidades do Estado de São Paulo e Barra Velha, em Santa Catarina." 12

Este caso nada mais é do que a prova de que o judiciário brasileiro tem mudado bastante em relação ao direito de família, tentando sempre se adequar às alterações que são vistas na família e na sociedade. O pai, por mais que tenha seus direitos de ver a criança e conviver com ela, não pode exercê-los de forma que venha a ferir os direitos do outro responsável e do infante, e caso insista em fazê-lo desta forma receberá punições do Estado como a demonstrada no recorte acima.

Já é consolidado no meio jurídico que nos casos em que alguma das partes cometer Alienação Parental de forma que o juiz considere grave, aquele poderá perder a Guarda do infante, ficando o outro genitor com todos os poderes e responsabilidades sobre a criança ou adolescente.

\section{6 \\ CIRCUNSTÂNCIAS EM QUE O GENITOR PERDE A GUARDA}

\subsection{SANÇÕES A PRATICA DA ALIENAÇÃO PARENTAL}

O Estatuto da Criança e do Adolescente (ECA) contempla diversos mecanismos de punição, que se mostram suficientes para inibir a alienação parental, entre eles podem ser citados a inversão da guarda, multa e chegando até mesmo a causar a suspensão da autoridade parental. Desta forma, não é necessária a inclusão de nenhuma sanção penal, principalmente porque os efeitos poderão ser prejudiciais à criança ou adolescente, que são os detentores dos direitos que se pretende assegurar com as Leis relativas à Alienação Parental. No entanto, de acordo com algumas situações específicas no caso concreto que o torne mais grave, pode ocorrer a caracterização de algum dos tipos penais já previstos, como é o caso da calúnia e consequentemente terá sanção penal contra o autor.

O responsável que praticar qualquer ato de alienação parental pode e deve ser punido de diversas maneiras, como por exemplo: Advertência, ampliação da convivência familiar em favor do outro genitor,

\footnotetext{
${ }^{12}$ GONÇALVES, Carlos Roberto. Direito civil brasileiro: direito das sucessões. 8. ed. São Paulo: Saraiva, 2014, p. 261.
} 
multa em favor do outro genitor, inversão da guarda, suspensão do poder familiar.

Como citado acima, até mesmo a destituição do poder familiar pode ser decretada pelo juiz quando, em virtude de comportamentos graves dos pais, sejam eles culposos ou dolosos. Tal medida será tomada pelo magistrado, sempre por meio de decisão fundamentada, de acordo com o previsto pelo art. 1.638 do Código Civil de 2002 que elenca as hipóteses em que é cabível tal medida, que se demonstra extrema demais para as outras situações, são elas:

\footnotetext{
I - Castigar imoderadamente o filho;

II - Deixar o filho em abandono;

III - Praticar atos contrários à moral e aos bons costumes;

IV - Incidir, reiteradamente, nas faltas previstas no artigo antecedente;

$\mathrm{V}$ - Entregar de forma irregular o filho a terceiros para fins de adoção.
}

Em se dizendo da suspensão do poder familiar, que é configurado pela perda temporária de tal poder, isto acontece por meio da justiça quando o juiz exerce seu poder geral de cautela após ser provocado por familiar da criança ou pelo Ministério Público, sem que haja a total perda do poder familiar do pai ou da mãe de maneira definitiva de sua autoridade parental, obsta o seu exercício. O Código Civil de 2002, em seu artigo 1.637 dispõe que:

Se o pai, ou a mãe, abusar de sua autoridade, faltando aos deveres a eles inerentes ou arruinando os bens dos filhos, cabe ao juiz, requerendo algum parente, ou o Ministério Público, adotar a medida que lhe pareça reclamada pela segurança do menor e seus haveres, até suspendendo o poder familiar, quando convenha.

O parágrafo único do artigo 1.637, complementa regulando que o exercício do poder familiar será suspenso ao pai ou à mãe que forem condenados por sentença irrecorrível, pelo cometimento de crime com pena que venha a ser maior do que dois anos de prisão.

É indiscutível que primeiramente deve-se prezar para que tanto a integridade física quanto a psíquica da criança e do adolescente sejam salvaguardadas pela legislação. Como exemplo de medidas que a Lei brasileira regula, pode-se citar a suspensão, a destituição e até mesmo a extinção do poder familiar, visando defender os interesses do menor, mesmo que para isso aconteça em detrimento do poder familiar, servindo este, sempre de acordo com o interesse da criança ou adolescente. 
Conforme a jurisprudência, há casos em que a mãe perde a Guarda dos filhos para o pai em razão de ter praticado atos taxados no rol do artigo 1.638 do Código Civil, em parte transcrito acima:

AGRAVO DE INSTRUMENTO $\mathrm{N}^{\circ}$ 823738-3, DE FORO CENTRAL DA COMARCA DA REGIÃO METROPOLITANA DE CURITIBA - $4^{\mathrm{a}}$ VARA DE FAMÍLIA AGRAVANTE: E. D. C. L. P. AGRAVADO: C. C. S. RELATOR: DES. RUY MUGGIATI. AGRAVO DE INSTRUMENTO. AÇÃO DE ALTERAÇÃO DE GUARDA. PRELIMINARES. CERTIDÃO DE INTIMAÇÃO - AUSÊNCIA - JUNTADA DE EXTRATO DO SISTEMA PROJUDI - VALIDADE. AUTENTICAÇÃO DE DOCUMENTOS - DESNECESSIDADE. ANTECIPAÇÃO DE TUTELA - CONTRADITÓRIO POSTERGADO. CONCESSÃO PROVISÓRIA DA GUARDA DOS FILHOS AO GENITOR PRÁTICA DE ATOS DE ALIENAÇÃO PARENTAL - NÃO AFASTAMENTO DOS FUNDAMENTOS DA DECISÃO OBSERVÂNCIA DA LEI N $12.318 / 2010$ - ATENDIMENTO AO MELHOR INTERESSE DAS CRIANÇAS - MANUTENÇÃO DA DECISÃO. ${ }^{13}$

\section{CONSIDERAÇÕES FINAIS}

Ao longo desta pesquisa de iniciação científica bastante se discutiu sobre a aplicação da Guarda Compartilhada e os efeitos dela. Tal tema é de total importância para a sociedade, ainda mais nos tempos atuais em que a família passa por enormes mudanças, devendo o Direito e as Leis seguirem o rumo dado pelas circunstâncias vistas em nossa sociedade, sempre buscando se adequar da melhor forma a fim de cuidar dos Direitos dos menores envolvidos nos processos de dissolução de casamentos e uniões estáveis.

Iniciou em uma análise mais ampla da matéria a fim de afunilar chegando de forma concisa aos seus pontos e características mais específicas. Neste caminho, verificou-se que o instituto da Guarda Compartilhada, apesar de ainda precisar de adaptações, passou por uma evolução enorme no último século e com certeza continuará sendo constantemente alterada para não se tornar um instrumento jurídico obsoleto. Sendo assim, o Estado deve sempre mantê-la condizente com a situação atual da família assegurando os Direitos dos menores perante a Constituição Federal em seus artigos 226 a 230.

13 Disponível em: <https://tj-pr.jusbrasil.com.br/jurisprudencia/2 1498389/8237383-pr-823738-3acordao-tjpr/inteiro-teor-21498390> Acesso em 09 jun. 2017. 
No desenrolar da pesquisa, pôde se perceber que o a Guarda Compartilhada depende não só do Estado e dos aplicadores do Direito, mas também de todas as partes envolvidas no processo que devem estar preparadas para agir de forma coerente com tal instituto, para que se consiga obter sucesso na formação da criança sem que ela tenha nenhum trauma psicológico ou a supracitada Síndrome da Alienação Parental, que pode trazer danos graves a saúde psíquica ou mesmo física do infante.

Feita as ponderações sobre o instituto da Guarda Compartilhada, nesta pesquisa, buscou-se caminhar na questão da defesa dos direitos das crianças envolvidas nas separações e disputas de guarda provindas delas.Constatou-se que, nos últimos anos, o Estado tem tentado evoluir em relação à adequada utilização dos recursos provindos da Lei para minimizar os efeitos da Alienação Parental e a combate-la a fim de reduzir cada vez mais sua incidência, apesar de ainda haver um longo e árduo caminho para que se consiga exterminar de vez essa prática da sociedade.

Ulteriormente, verificou-se que para a correta adequação do regime de Guarda dos filhos, deve-se usar não só o Código Civil, mas também a Constituição Federal, sempre pautadas pelo bom senso e pelo princípio de que a importância da família não pode ser diminuída aos aspectos financeiros que são atrelados à separação judicial, principalmente quando se tem crianças envolvidas.

Portanto, por mais que a Guarda Compartilhada traga incontáveis benefícios tanto para a criança quanto para os pais e seja definida pela lei como regra geral, não devendo ser aplicada apenas nos casos em que realmente não for possível sempre devem ser sopesados os prós e contras de cada regime de guarda no caso concreto, sendo assim, não é possível dizer qual é a certa ou errada, apenas a mais condizente com a situação.

É totalmente necessário que não só os juristas, legisladores e demais aplicadores do direito deem a devida importância ao assunto em todo o mundo, mas por ser um assunto que envolve a família, é necessário que também haja um envolvimento de ONG's, projetos sociais e demais institutos para que o assunto se aproxime mais da realidade, da sociedade, trazendo para um plano prático a questão da divisão de Guardas, fazendo com que as pessoas pensem sobre isso, discutam sobre isso e busquem cada vez mais se informar sobre o assunto para que possam agir da melhor forma em relação aos filhos nesse momento tão complicado que é o divórcio.

Embora a Guarda Compartilhada seja incontestavelmente aceita entre os aplicadores do direito, na sociedade ela não é unanimidade, ainda mais quando se trata da guarda do próprio filho, tem-se notado que durante 
a disputa judicial dos filhos, a maioria dos pais acaba tomando atitudes com o propósito de fazer com que o juiz decrete a Guarda Unilateral, chegando até à atitudes absurdas, como a abordada no item 4.2 desta pesquisa. Sendo assim, é demasiado claro que a Lei precisa cada vez mais evoluir em face do seu propósito, que é o bem das crianças. Porém, deve haver também projetos de disseminação da Guarda Compartilhada, para que todos saibam do que realmente se trata e abram as portas para ela quando estiverem envolvidas em um processo de divisão de guarda.

À vista disso, deve haver redobrada cautela ao analisar um caso de divisão da guarda de um menor, pois como demonstrado nesta pesquisa, isso afeta diretamente a vida da criança, tanto em seu dia-a-dia quanto nos aspectos ligados ao afeto provindo das famílias que devem ser sempre congruentes às crianças, por mais que seus pais não tenham mais um relacionamento.

Desse modo, é inquestionável o dever dos pais ou responsáveis pelo infante de não só cobrir os gastos que ele possa vir a trazer ao outro responsável, mas o dever de conviver com ele, criar laços afetivos que fazem toda a diferença na vida dessa criança, que além de tudo está em fase de desenvolvimento da sua personalidade, que com certeza será afetada pela sua relação com sua família, independentemente de qual for sua composição ou se passaram a formar duas famílias, que juntas lhe dão a devida atenção.

\section{REFERÊNCIAS BIBLIOGRÁFICAS}

COELHO, Fábio Ulhoa Curso de direito civil: família e sucessões. 5. ed. São Paulo: Saraiva, 2012.

DIAS, Maria Berenice, Manual de direito das famílias I. 10. ed. São Paulo: Revista dos Tribunais, 2015.

FONTES, Simone Roberta, Guarda Compartilhada-doutrina e prática. 1.ed., 2009. v.1

GONÇALVES, Carlos Roberto. Direito civil brasileiro: direito de família. 9. ed. São Paulo: Saraiva, 2012.

LEITE, Aline Ferreira Dias. A disputa pela guarda dos filhos e a guarda compartilhada: A atuação dos assistentes sociais judiciários. Dissertação (Mestrado em Assistência Social) - Pontifícia Universidade Católica de São Paulo (PUC-SP), 2010.

MADALENO, Ana Carolina Carpes e Rolf, Síndrome da Alienação Parental. Importância da Deteç̧ão. Aspectos Legais e Processuais 
ROSA, da Paulino Conrado. Nova lei da guarda compartilhada. São Paulo: Saraiva, 2015.

SOUZA, A.M. Síndrome da Alienação Parental: um novo tema nos juízos da família. 1.ed., 2010, Cortez, São Paulo, SP

TARTUCE, Flávio. Direito civil: direito de família. 9. ed. Rio de Janeiro: Forense, 2014

VENOSA, Sílvio de Salvo. Direito civil: direito de família.13. ed. São Paulo. Atlas, 2013.

VENOSA, Sílvio de Salvo. Direito civil: direito de família. v.6. 14.ed. São Paulo: Atlas, 2014. 